\title{
Further Research on Hardenability of Ti-1023 $\beta$ Alloy Leading to a New DOE
}

\author{
Bohumil Prazak \\ b.prazak-13@student.Iboro.ac.uk \\ Loughborough University
}

\section{Abstract}

As part of a treatise on the hardenability of Ti-1023, a summary about the nucleation mechanisms of primary and secondary alpha, the viability of two-step aging, and existence of precipitation-free zones is provided. Assumptions are given on the nucleation mechanism of primary alpha particles and the effect of higher beta stabiliser content on stress-induced martensitic transformation. It is reminded that further research into two-step aging would be beneficial. A proposed design of the experiment deals with the existence of martensite in stressed samples, so that the martensitic transformation is minimized by an increased content of beta stabilisers, volume fraction of primary alpha, and beta grain size. Finally, a microstructure with stress-induced omega particles as precursors of secondary alpha particles may result in a better trade-off of mechanical properties; it is suggested that this be explored.

\section{Introduction}

Ti-1023 is a beta titanium alloy designed to provide better mechanical properties than Ti64 and was patented by Timet in 1974 [1]. This alloy is currently available in three modifications AMS 4984, 4986, 4987 and finds an application in aircraft structural parts such as landing gear, actuators, flap tracks, rotor heads, fittings and fasteners [2] due to material properties such as its excellent combination of strength, ductility, toughness, machinability, weight, superior fatigue properties, corrosion resistance, deep hardenability with reasonable high-temperature strength and creep stability [3][4][5][6][7][8][9]. Due to a wide range of chemical composition, the molybdenum-aluminium equivalent [Mo-Al] eq can acquire values app. 5.3-10.4 [10][2], and Ti-1023 is thus positioned predominantly as a near beta alloy. The beta transus for a varying composition is not known but some reported values are between $788-805^{\circ} \mathrm{C}[11][4][12][13]$. A varying composition influencing mainly the $\beta$-transus temperature, microstructure and material properties has been causing confusion among researchers since its inception due to possible formation of martensite upon quenching to room temperature, especially when quenching thick sections [4][14][15][16][17][18] [19].

Ti-1023 is beta forged to increase fracture toughness and finish alpha-beta forged to keep a sufficient level of fracture toughness and to improve ductility [3]. The alloy composition and thermomechanical processing - such as forging history and heat treatments - have an impact on the mechanical properties primarily by a modification of the volume fraction, morphology and distribution of a phase [20].

The resulting microstructure of samples quenched from above or below the beta transus and strengthened by $a$-aging has very good fatigue cycle properties and crack growth resistance [21][6]. Hence the major interest lies in tensile strength, elongation and fracture toughness and their trade-off. Depending on thermomechanical treatment, the ultimate yield strength varies ca. 260$1530 \mathrm{MPa}$, the uniform elongation $0-18 \%$ and the fracture toughness $20-70 \mathrm{MPa} / \mathrm{m}[22][4][7]$.

Especially for small cylindrical parts, it seems these could be designed in a more efficient and effective process than currently available giving a better trade-off of mechanical properties and reduced cost. A consideration will be given to influence of stressinduced omega phase to clarify whether Ti-1023 finds new applications.

\section{Current situation}

The following text will summarize the mechanisms of nucleation of primary alpha $a_{p}$ and secondary alpha $a_{s}$ phase, two-step aging, precipitation free zones and stress-induced omega phase.

The primary alpha $a_{p}$ phase exists in samples processed in the alpha-beta field. Tang et al. [23] suggested that with decreasing content of beta stabilisers in the titanium alloys the mechanism of formation of $a_{p}$ lamellae changes from sympathetic nucleation to interface instability. As for Ti-7Mo-3Nb-3Cr-3Al alloy with the [Mo-Al $]_{\mathrm{eq}}=8.64$, both mechanisms (mixed) were observed. 
Hence, it is presumed that $\mathrm{Ti}-1023$ with the $[\mathrm{Mo}-\mathrm{Al}]_{\mathrm{eq}}=5.3-10.4$ can go through sympathetic nucleation at a higher range, mixed at middle and possibly interface instabilities at a lower range. The impact of various mechanisms of formation of $a_{p}$ lamellae on mechanical properties in general is not clear.

The mechanism of nucleation of the secondary alpha $a_{s}$ in the absence of pre-existing isothermal omega $\omega_{i}$ phase was documented on many occasions such as in step-quenching from the solution treatment temperature [24], rapid heating [25] or up-quenching [26] or mixed heating [27] to aging temperature and suppression of $\omega_{i}$ formation as a consequence of a higher content of aluminium or oxygen [28]. Terlinde et al. [22] described a secondary alpha $a_{\mathrm{s}}$ of size $3-8 \times 0.1$ micron that were created in an autocatalytic manner in the case of a high heating rate (not specified) to an aging temperature $>400^{\circ} \mathrm{C}$ in Ti-1023 alloy not forming martensite upon beta quenching. For the purpose of creation of an isothermal transformation diagram for Ti-1023, Toran and Biederman [14] experimented with step quenching from above the beta transus temperature and confirmed that above $550^{\circ} \mathrm{C}$, the acicular secondary alpha $a_{\mathrm{s}}$ formed upon annealing from beta phase. Below $550^{\circ} \mathrm{C}$, the acicular martensite formed first. However, neither the composition of this alloy nor any results of mechanical testing were available. Most likely the annealed microstructure of samples formed by step-quenching from above the beta transus and samples previously quenched to room temperature and rapidly heated or up-quenched to the same temperature is very similar despite the fact that the linear defects forming the athermal omega $\omega_{\mathrm{a}}$ embryos transform to $\omega_{\mathrm{a}}$ in the latter case [29][25][26].

The location of nucleation of secondary alpha $a_{s}$ particles assisted directly or indirectly by isothermal omega $\omega_{i}$ particles has received a lot of attention recently, especially in the case of samples beta quenched to room temperature. Nucleation of secondary alpha $a_{s}$ particles has been presumed at the $\beta-\omega_{i}$ interfaces for both high and low misfit alloys [30][31][32][33] [34], in $\omega_{i}$ particles [35], near $\beta-\omega_{i}$ interface [36] and instead of $\omega_{i}$ particles [27]. During aging, Ti-1023 behaves as an alloy with a high linear misfit. The isothermal omega $\omega_{i}$ particles adopt a cubical shape to minimize the total elastic strain. The lattice misfit increases until exceeding a critical value causing formation of interfacial dislocations where preferentially the secondary alpha $a_{s}$ nucleates. Hence, secondary alpha $a_{s}$ particles nucleate at the $\beta-\omega_{i}$ interfaces [31][37]. Beta solution treated and water quenched Ti-1023 samples exhibited three different forms of isothermal omega $\omega_{i}$ particles such as nondescript, ellipsoidal and cubical depending on aging temperature and time [4]. Hadjadj et al. [38] experimented with alpha-beta solution treated water quenched Ti-1023 alloy. The atomic probe measurements of the directly aged specimens at a temperature of $300^{\circ} \mathrm{C}$ showed isothermal omega $\omega_{\mathrm{i}}$ zones depleted in all alloying elements and after a longer annealing time also secondary alpha $a_{\mathrm{s}}$ zones with a higher content of aluminium. The authors presumed that secondary alpha $a_{s}$ precipitated preferentially at the $\beta-\omega_{i}$ interface. Three different types of nucleation mechanism of secondary alpha $a_{s}$ phase during aging were observed such as uniform at temperature $<450^{\circ} \mathrm{C}$, sympathetic at $>400^{\circ} \mathrm{C}$ and preferential along $\beta-\beta$ grain boundaries at $>650^{\circ} \mathrm{C}$. The achievable strength was the highest in the uniform nucleation scheme [4]. At low heating rates, it was observed that formation of isothermal omega $\omega_{i}$ particles was being replaced by fine secondary alpha $a_{s}$ at aging temperatures $>400^{\circ} \mathrm{C}$ in Ti-1023 alloy not forming martensite upon beta quenching [22].

A two-step aging process led to an improved combination of strength and ductility due to pre-existing $\omega_{i}$ particles which directed the distribution and morphology of $a_{s}$ particles [39][40]. Ellipsoidal isothermal omega $\omega_{i}$ particles formed during a short anneal of a beta solution treated and water quenched Ti- 1023 sample at $400^{\circ} \mathrm{C}$. The second anneal at $300^{\circ} \mathrm{C}$ for $45 \mathrm{~min}$ resulted in cubical shape $\omega_{i}$ particles [4]. A two-step aged Ti-1023 beta quenched sample to room temperature had slightly larger secondary alpha $a_{s}$ particles and gave very good fracture toughness and strain [7]. However, more sophisticated research into mechanical properties is not available.

Quazi et al. [41] observed precipitate free zones, presumably due to grain boundaries acting as sinks for oxygen in samples aged at increased aging temperature in high-oxygen-enriched Ti-Nb alloys. Mantri et al. [42] and Sakamoto et al. [43] observed an improved ductility in samples forming precipitate free zones. Precipitate free zones are not typical for Ti-1023, however Duerig et al. [4] described a thick layer of grain boundary alpha forming at high aging temperature $680^{\circ} \mathrm{C}$ after $2000 \mathrm{~min}$ in an alloy with an oxygen content $0.15 \mathrm{wt}$ pct. Precipitate free zones of a slightly smaller width are apparent from the SEM pictures.

The omega phase has been satisfactorily stress-induced previously by cold rolling or compression at room temperature [44][45] [46][47]. Similar experimental work relating to Ti-1023 has not been located probably due to the stress-induced martensitic transformation typical for this alloy [48][4] and the previously mentioned existence of martensite upon beta quenching. The stress-induced martensitic transformation is however avoidable by both increasing of a volume fraction of primary alpha $a_{p}$ [4] and increasing the beta grain size [49][50]. Presumably, with a higher beta stabiliser content, the effect of stress-induced martensitic transformation reduces as well. It is further not clear how the structure of the samples changes upon application of various strains and strain rates during an upsetting process at room temperature.

\section{Further work with Ti-1023}

Barriobero-Vila et al. [19] conducted probably the most sophisticated experimental work with differential scanning calorimetry (DSC) and high-energy X-ray diffraction (HEXRD)describing the phase transformations in beta quenched Ti-1023 when heating from room temperature to $600^{\circ} \mathrm{C}$ under various heating rates. The [Mo-Al] eq was low at 6.36 and orthorhombic martensite $a^{\prime \prime}$ 
was found in a retained $\beta$ phase matrix upon quenching. Apart from orthorhombic martensite, athermal omega $\omega_{\mathrm{a}}$ was also found. Depending on a heating rate the orthorhombic martensite decomposed to beta phase, or also directly to omega phase. The authors suggested a diffusion-controlled mechanism of growth of isothermal omega $\omega_{i}$ from beta at low heating rates and formation of isothermal omega $\omega_{i}$ from orthorhombic martensite at the highest heating rate. An extremely high volume fraction of isothermal omega $\omega_{\mathrm{i}}$ about $70-80 \%$ of the entire volume was found at temperature ca. $250-400^{\circ} \mathrm{C}$ for a high heating rate $50^{\circ} \mathrm{C} / \mathrm{min}$. Considering the fact, secondary alpha $\alpha_{\mathrm{s}}$ likely precipitates preferentially at $\beta-\omega_{\mathrm{i}}$ interface [38], it might be beneficial to explore the effect of heating rate and the volume fraction of isothermal omega $\omega_{i}$ for precipitation of secondary alpha $a_{s}$.

\section{Design of experiment}

The primary objective of this paper was to provide background research to develop a new route to hardening of cylindrical parts

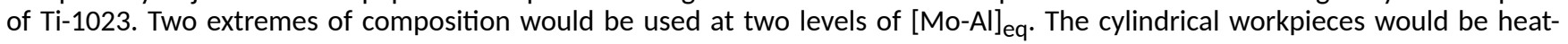
treated at four levels, two above and two below beta transus. For both types of material this allows a determination of a suitable beta grain size and a content of primary alpha $a_{p}$ to avoid either type or martensitic transformation. The cylindrical samples shall be further upset at room temperature at two levels such as 5 and $15 \%$ at two levels of strain rate.

\section{Summary}

The author believes that given experimental work will lead to a more efficient and effective process achieving superior mechanical properties of small cylindrical parts. In addition, several research suggestions have been given that could be clarified as part of planned experimental work.

\section{$\underline{\text { References }}$}

[1] J. D. Cotton, R. D. Briggs, R. R. Boyer, S. Tamirisakandala, P. Russo, N. Shchetnikov, and J. C. Fanning, "State of the art in beta titanium alloys for airframe applications," JOM, vol. 67, no. 6. Springer, pp. 1281-1303, 2015.

[2] Titanium Metals Corporation, "Timetal 10-2-3," 2018. [Online]. Available: http://www.timet.com/assets/local/documents/datasheets/metastablebetaalloys/10-2-3.pdf.

[3] C. C. Chen and R. R. Boyer, "Practical considerations for manufacturing high-strength Ti-10V-2Fe-3Al alloy forgings," JOM, vol. 31, no. 7, pp. 33-39, 1979.

[4] T. W. Duerig, G. T. Terlinde, and J. C. Williams, "Phase transformations and tensile properties of Ti-10V-2Fe-3Al," Metall. Trans. A, vol. 11, no. December 1980, pp. 1987-1998, 1987.

[5] R. R. Boyer and G. W. Kuhlman, "Processing properties relationships of Ti-10V-2Fe-3Al," Metall. Trans., vol. 18, no. December, pp. 2095-2103, 1987.

[6] G. W. Kuhlman, A. K. Chakrabarti, T. L. Yu, R. Pishko, and G. Terlinde, "LCF, fracture toughness, and fatigue/fatigue crack propagation resistance optimization in Ti-10V-2Fe-3Al alloy through microstructural modification," Metall. Soc., pp. 171192, 1987.

[7] G. Terlinde, H.-J. Rathjen, and K.-H. Schwalbe, "Microstructure and fracture toughness of the aged $\beta$-Ti Alloy Ti-10V-2Fe3Al," Metall. Trans., vol. 19, no. 4, pp. 1037-1049, 1988.

[8] G. R. Yoder, R. R. Boyer, and L. Cooley, "Corrosion fatigue resistance of Ti-10V-2Fe-3Al alloy in salt water," in Sixth World Conference on Titanium, 1988, pp. 1741-1746.

[9] S. K. Jha and K. S. Ravichandran, "High-cycle fatigue resistance in beta-titanium alloys," JOM, vol. 52, no. 3, pp. 30-35, 2000.

[10] H. W. Rosenberg, "Titanium alloying in theory and practice," in The Science, Technology and Application of Titanium, Elsevier, 1970, pp. 851-859.

[11] C. C. Chen and R. R. Boyer, "Practical considerations for manufacturing high-strength Ti-10V-2Fe-3Al alloy forgings," JOM, vol. 31, no. 7, pp. 33-39, 1979.

[12] V. V Balasubrahmanyam and Y. V. R. K. Prasad, "Hot deformation mechanisms in metastable beta titanium alloy Ti-10V2Fe-3Al," Mater. Sci. Technol., vol. 17, no. 10, pp. 1222-1228, 2001.

[13] L. Lei, X. Huang, M. Wang, L. Wang, J. Qin, H. Li, and S. Lu, "Effect of hot compressive deformation on the martensite transformation of Ti-10V-2Fe-3Al titanium alloy," Mater. Sci. Eng. A, vol. 530, pp. 591-601, 2011. 
[14] J. R. Toran and R. R. Biederman, "Phase transformation study of Ti-10V-2Fe-3Al," Titanium'80 Sci. Technol., pp. 1491-1500, 1980.

[15] D. G. Robertson and H. B. McShane, "Isothermal hot deformation behaviour of metastable $\beta$ titanium alloy Ti-10V-2Fe3Al," Mater. Sci. Technol., vol. 13, no. 7, pp. 575-583, 1997.

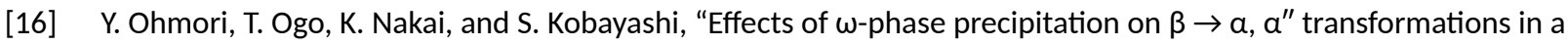
metastable $\beta$ titanium alloy," Mater. Sci. Eng. A, vol. 312, no. 1-2, pp. 182-188, 2001.

[17] M. Jackson, N. G. Jones, and D. Dye, "Effect of initial microstructure on plastic flow behaviour during isothermal forging of Ti-10V-2Fe-3Al," Mater. Sci. Eng. A, vol. 501, no. 1-2, pp. 248-254, 2009.

[18] G. Z. Quan, W. Q. Lv, J. T. Liang, S. A. Pu, G. C. Luo, and Q. Liu, "Evaluation of the hot workability corresponding to complex deformation mechanism evolution for Ti-10V-2Fe-3Al alloy in a wide condition range," J. Mater. Process. Technol., vol. 221, pp. 66-79, 2015.

[19] P. Barriobero-Vila, G. Requena, F. Warchomicka, A. Stark, N. Schell, and T. Buslaps, "Phase transformation kinetics during continuous heating of a $\beta$-quenched Ti-10V-2Fe-3Al alloy," J. Mater. Sci., vol. 50, no. 3, pp. 1412-1426, 2015.

[20] G. T. Terlinde, T. W. Duerig, and J. C. Williams, "Microstructure, tensile deformation, and fracture in aged ti 10V-2Fe-3Al," Metall. Trans. A, vol. 14, no. 10, pp. 2101-2115, 1983.

[21] T. W. Duerig, J. E. Allison, and J. C. Williams, "Microstructural influences on fatigue crack propagation in Ti-10V-2Fe-3Al," Metall. Trans. A, vol. 16, no. 5, pp. 739-751, 1985.

[22] G. T. Terlinde, T. W. Duerig, and J. C. Williams, "The effect of heat treatment on microstructure and tensile properties of Ti10V-2Fe-3Al," Titan. '80 Sci. Technol., vol. 2, pp. 1571-1581, 1980.

[23] B. Tang, H. Kou, X. Zhang, P. Gao, and J. Li, "Study on the formation mechanism of a lamellae in a near $\beta$ titanium alloy," Prog. Nat. Sci. Mater. Int., vol. 26, no. 4, pp. 385-390, 2016.

[24] S. Nag, Y. Zheng, R. E. A. Williams, A. Devaraj, A. Boyne, Y. Wang, P. C. Collins, G. B. Viswanathan, J. S. Tiley, B. C. Muddle, R. Banerjee, and H. L. Fraser, "Non-classical homogeneous precipitation mediated by compositional fluctuations in titanium alloys," Acta Mater., vol. 60, no. 18, pp. 6247-6256, 2012.

[25] N. G. Jones, R. J. Dashwood, M. Jackson, and D. Dye, " $\beta$ Phase decomposition in Ti-5Al-5Mo-5V-3Cr," Acta Mater., vol. 57, no. 13, pp. 3830-3839, 2009.

[26] Y. Zheng, R. E. A. Williams, J. M. Sosa, Y. Wang, R. Banerjee, and H. L. Fraser, "The role of the $\omega$ phase on the non-classical precipitation of the a phase in metastable $\beta$-titanium alloys," Scr. Mater., vol. 111, pp. 81-84, 2016.

[27] Y. Zheng, R. E. A. Williams, J. M. Sosa, T. Alam, Y. Wang, R. Banerjee, and H. L. Fraser, "The indirect influence of the $\omega$ phase on the degree of refinement of distributions of the a phase in metastable $\beta$-Titanium alloys," Acta Mater., vol. 103, pp. 165-173, 2016.

[28] J. C. Williams, B. S. Hickman, and D. H. Leslie, "The effect of ternary additions on the decompositon of metastable betaphase titanium alloys," Metall. Trans., vol. 2, no. 2, pp. 477-484, 1971.

[29] J. C. Williams, D. de Fontaine, and N. E. Paton, "The $\omega$-phase as an example of an unusual shear transformation," Metall. Trans., vol. 4, no. 12, pp. 2701-2708, 1973.

[30] M. J. Blackburn and J. C. Williams, "Phase transformations in Ti-Mo and Ti-V alloys," Trans. Metall. Soc. AIME, pp. 2461$2469,1968$.

[31] J. C. Williams and M. J. Blackburn, "Influence of misfit on morphology and atability of omega phase in Titanium - transition metal alloys," Trans. Metall. Soc. Aime, vol. 245, no. 10, pp. 2352-2355, 1969.

[32] S. Nag, R. Banerjee, R. Srinivasan, J. Y. Hwang, M. Harper, and H. L. Fraser, " $\omega$-Assisted nucleation and growth of a precipitates in the Ti-5Al-5Mo-5V-3Cr-0.5Fe $\beta$ titanium alloy," Acta Mater., vol. 57, no. 7, pp. 2136-2147, 2009.

[33] T. Li, D. Kent, G. Sha, M. S. Dargusch, and J. M. Cairney, "The mechanism of $\omega$-assisted a phase formation in near $\beta-T i$ alloys," Scr. Mater., vol. 104, pp. 75-78, 2015.

[34] Y. Zheng, R. E. A. Williams, D. Wang, R. Shi, S. Nag, P. Kami, J. M. Sosa, R. Banerjee, Y. Wang, and H. L. Fraser, "Role of $\omega$ phase in the formation of extremely refined intragranular a precipitates in metastable $\beta$-titanium alloys," Acta Mater., vol. 
103, pp. 850-858, 2016.

[35] F. Prima, P. Vermaut, G. Texier, D. Ansel, and T. Gloriant, "Evidence of a-nanophase heterogeneous nucleation from $\omega$ particles in a $\beta$-metastable Ti-based alloy by high-resolution electron microscopy," Scr. Mater., vol. 54, no. 4 SPEC. ISS., pp. 645-648, 2006.

[36] S. Azimzadeh and H. J. Rack, "Phase transformations in Ti-6.8Mo-4.5Fe-1.5Al," Metall. Mater. Trans. A, vol. 29, no. 10, pp. 2455-2467, 1998.

[37] B. S. Hickman, "Omega phase precipitation in alloys of titanium with transition metals," Trans. Metall. Soc. AlME, vol. 245, pp. 1329-1335, 1969.

[38] L. Hadjadj, M. H. Campagnac, A. Vassel, and A. Menand, "Atom-probe and TEM study of the isothermal $\omega$ and secondary a phases in a Ti-10V-2Fe-3Al alloy," Microsc. Microanal. Microstruct., vol. 3, no. 6, pp. 471-482, 1992.

[39] M. G. Mendiratta, G. Lütjering, and S. Weissman, "Strength increase in Ti 35 Wt Pct Nb through step-aging," Metall. Trans., vol. 2, no. 9, pp. 2599-2605, 1971.

[40] G. M. Pennock, H. M. Flower, and D. R. F. West, "The control of a precipitation by two step ageing in $\beta$ Ti-15Mo," Titanium, pp. 19-22, 1980.

[41] J. I. Qazi, B. Marquardt, L. F. Allard, and H. J. Rack, "Phase transformations in Ti-35Nb-7Zr-5Ta-(0.06-0.68)O alloys," in Materials Science and Engineering C, 2005, vol. 25, no. 3, pp. 389-397.

[42] S. A. Mantri, D. Choudhuri, A. Behera, J. D. Cotton, N. Kumar, and R. Banerjee, "Influence of fine-scale alpha precipitation on the mechanical properties of the beta titanium alloy Beta-21S," Metall. Mater. Trans. A, vol. 46, no. 7, pp. 2803-2808, 2015.

[43] T. Sakamoto, K. Takiue, Y. Higaki, S. Kobayashi, and K. Nakai, "Effect of a phase nucleating at transition phase and dislocation on mechanical properties in metastable $\beta$ titanium alloy Ti-6.8Mo-4.5Fe-1.5AI," J. Japan Inst. Met., vol. 79, no. 12, pp. 651-656, 2015.

[44] T. S. Kuan, R. R. Ahrens, and S. L. Sass, "The stress-induced omega phase transformation in Ti-V alloys," Metall. Trans. A, vol. 6, no. 9, pp. 1767-1774, 1975.

[45] H. Ohyama, H. Nakamori, Y. Ashida, and T. Maki, "Effects of cold deformation on the morphology of a precipitates in $\beta$ titanium alloys," ISIJ Int., vol. 32, no. 2, pp. 222-231, 1992.

[46] X. Zhao, M. Niinomi, M. Nakai, and J. Hieda, "Effect of deformation-induced $\omega$ phase on the mechanical properties of metastable $\beta$-type Ti-V alloys," Mater. Trans., vol. 53, no. 8, pp. 1379-1384, 2012.

[47] H. Liu, M. Niinomi, M. Nakai, and K. Cho, "Athermal and deformation-induced $\omega$-phase transformations in biomedical beta-type alloy Ti-9Cr-0.20," Acta Mater., vol. 106, pp. 162-170, 2016.

[48] T. W. Duerig, J. Albrecht, D. Richter, and P. Fischer, "Formation and reversion of stress induced martensite in Ti-10V-2Fe3Al," Acta Metall., vol. 30, no. 12, pp. 2161-2172, 1982.

[49] A. Bhattacharjee, S. Bhargava, V. K. Varma, S. V Kamat, and A. K. Gogia, "Effect of $\beta$ grain size on stress induced martensitic transformation in $\beta$ solution treated Ti-10V-2Fe-3Al alloy," Scr. Mater., vol. 53, no. 2, pp. 195-200, 2005.

[50] A. Bhattacharjee, V. K. Varma, S. V Kamat, A. K. Gogia, and S. Bhargava, "Influence of $\beta$ grain size on tensile behavior and ductile fracture toughness of titanium alloy Ti-10V-2Fe-3Al,” Metall. Mater. Trans. A, vol. 37, no. 5, pp. 1423-1433, 2006. 